\title{
The Participation in a Research and Study Group: A Collective Discourse Perspective
}

\author{
Maria Cristina Lima Paniago, Katia Alexandra de Godoi e Silva \\ Programa de Pós-graduação em Educação, Universidade Católica Dom Bosco, Campo Grande, Brasil \\ Email: cristina@ucdb.br; katigodoi@gmail.com
}

Received 1 July 2015; accepted 19 December 2015; accepted 22 December 2015

Copyright (C) 2015 by authors and Scientific Research Publishing Inc.

This work is licensed under the Creative Commons Attribution International License (CC BY). http://creativecommons.org/licenses/by/4.0/

(c) (i)

\begin{abstract}
This research aims to analyze the collective discourse from members of a research and study group on their participation. In order to achieve this goal, we use a quantitative and qualitative approach. For the analysis of quantitative questions, we choose to use graphics in order to illustrate the opinion of the group members. In the analysis of qualitative questions, we choose to bring the members opinions in a single speech, using the Collective Subject Discourse methodology. Overall, the results point to the lack of time of the members to participate in the group and to the importance of deepening and glimpsing other studies about participation.
\end{abstract}

\section{Keywords}

Research Group, Collective Subject Discourse, Participation

\section{Introduction}

The aim of this study is to analyze the collective discourse of the members of a research group, both with regards to a general review of the analyzed content, the participant researcher of the group, as well as their own group membership.

From this goal comes the following question: How does one develop participation in a research group?

To answer this question we used a quantitative and qualitative methodological approach, the latter based on the Collective Subject Discourse (CSD) (Lefevre \& Lefevre, 2005, 2012). In this study, these approaches are utilized as complementary, that is the two approaches can be analyzed in its various aspects, and they generate quantitative research questions to be qualitatively deepen, and vice versa.

Besides this introduction, this study has five parts: the first, a history about the Group of Research and Studies in Educational Technology and Distance Education (GETED); the second, the research methodology; the third, the results and the fourth, the analysis of these results, which were analyzed in light of theoretical frameworks 
that could support the issues of the participatory process (Freire, 1991, 2003; Lave \& Weger, 1991; Paniago, 2007) of the members the group; the last part deals with the conclusion of the study submitted.

\section{The GETED}

The Conselho Nacional de Desenvolvimento Científico e Tecnológico (CNPq) registers the country's research groups in Brazil. Therefore, it maintains a Research Groups Directory with recording information, which is available for consultation, and it assigns a certification seal.

According to the summary statistics for the year 2010 area, CNPq has 27,523 research groups. The area of Education has 2,236 groups, which represent $8.1 \%$ of groups from all areas of knowledge.

The approach of this work lies in an initial study on the collective discourse from members of the Group of Research and Studies on Educational Technology and Distance Education (Grupo de Pesquisa e EstudosemTecnologia Educacional e Educação a Distância-GETED).

This group, certified by CNPq, was created in 2006 by the researchers PhD. Maria Cristina Lima Paniago and $\mathrm{PhD}$. Arlinda Cantero Dorsa.

It aims to promote spaces for discussion, training, sharing, exchanging, questioning and developing practices, jobs, research, materials, concepts, experiences and networks related to the integration of Information and Communication Technologies (ICT) in educational settings, both in person and distance training and teaching practices. As well as, it provides theoretical and practical information to people interested in issues about educational technology and distance education, in the sense of promoting: literacy; training; and critical, reflective, proactive, participatory and collaborative technological literacy.

The GETED currently brings together 12 researchers (Universidade Católica Dom Bosco-UCDB; Universidade Estadual de Mato Grosso do Sul-UEMS; Universidade Federal de Mato Grosso do Sul-UFMS and Research Centre for Migration and Intercultural Relations-CEMRI, the Open University) and eight students (undergraduate, Masters and $\mathrm{PhD}$ ) from UCDB and other institutions registered in CNPq. In addition, teachers from state and municipal network of Mato Grosso do Sul Education, all of them with a common interest in researching and studying ICT and their relationships in the teaching practice and Distance Education.

These researchers and students meet in person meetings, which take place every 15 days, and at distance, through lectures using the Hangout and Ning tools. In addition, it maintains a closed group on Facebook social network.

\section{Methodology}

As previously announced, this study provides two data analysis approaches: quantitative and qualitative. One complements the other, since they are characterized as an effort to broaden our knowledge about discourse of GETED members.

Thus, for the part of this study we collected data at two different times: June 2014 and December 2014 using two instruments.

The data collection instrument used was the questionnaire. To Gil (1994), the questionnaire is the form most often used to collect data. It is a list of questions that the respondent alone answers, checking or writing the answers.

Thus, at the end of the first half of 2014, we call on GETED members to answer an online questionnaire using Google Docs tool, containing quantitative questions regarding to the contents discussed in the meetings, as well as related to the group's researchers. That same questionnaire also had qualitative character issues, in which group members completed the spaces to enrich their opinions with comments and suggestions (e.g. I could have used more if..., I had a certain resistance...; It was great... I did not like...; I really enjoyed... Missed..., I suggest...).

At the end of the second semester we also asked GETED members to answer a printed questionnaire which included three parts: quantitative, which addressed issues related to the content covered in the lectures, about the researchers and lecturers, and also about the participation of individual members and the group; qualitative, with spaces so that the members could enrich their opinions with comments and suggestions (e.g. I could have taken longer...; It was great...; I did not like...; Missed...); with suggestions and proposals about topics for lectures in 2015.

Before proceeding with the explanations about the part the questionnaires analyses, it is noteworthy to justify 
the amount of members who responded the questionnaires. Since this is a quantitative and qualitative study we considered significant the sampling of respondents, as both approaches contributed to the interpretation of the presented data, both in the first and the second questionnaires.

The sampling we work in this study is called "sampling by accessibility", that is, we select the elements to which we had access. According to Silva (2005), it is a type of non-probability sampling, because it has no relation to the statistics, so it is less accurate and it can be used in qualitative studies.

Thus, in the first questionnaire, out of twenty members from GETED, we have a five respondents sampling. We believe that this figure is due to the fact that not all group members have had time to respond to the online questionnaire.

In the second questionnaire, it had a sampling of ten respondents. This number is justified by the fact that not all group members were present at the last meeting in person.

Our assumption is that the absence of respondent members may be related to lack of time and the effective participation in the group.

In order to bring an analysis of the two questionnaires, we made a cut and we chose to treat the following issues: quantitative (in relation to the content addressed, the researcher and participation); qualitative (I could have used more if...; It was great ...; I did not like...; Missed... Suggestions...).

For the analysis of quantitative questions we chose to use graphics to illustrate the opinion of the members. In the analysis of qualitative issues we chose to bring the opinions of members in a single, collective discourse.

But how can we empirically generate a set of open questions into collective opinions?

To answer this question, we used the Collective Subject Discourse (CSD) methodology.

According to Lefevre \& Lefevre (2005) and Lefevre \& Lefevre (2012), the CSD rescues the thought of a community preparing a speech about a certain topic.

To prepare the collective thought, it is necessary to add qualitatively equal individual thoughts, adding elements that make up "similar responses of different individuals", transforming the answers in a collective discourse with meaning.

The development of a collective discourse process with meaning is complex and, according to Lefevre \& Lefevre (2012), transactions are necessary or methodological approaches:

- Key Expressions (KE) — selected portions of each statement that best describe the content of the testimony.

- Central Ideas (CI) - ideas that describe succinctly and accurately the meaning of the KE of each analyzed speech. The CI is also called Category.

- Collective Subject Discourse (CSD)—meeting in one speech-synthesis, drawn up in the first person singular, the KE which has the same CI.

To create the CSD, in this study, the KE were initially chosen from the related responses the two questionnaires (see item A); then the CI of each KE had been selected; and finally, the construction of the CI. Created the CI, the CSD was prepared for each CI, transforming the answers in a collective discourse.

For this study, we bring as CI, the qualitative parts of the introductory sentences of the questionnaire itself: I could have taken longer...; It was great...; I did not like...; Missed..., Suggestions...

Thus, in the text, it will be possible to identify the operations 2 and 3 (CI and CSD), as shown in the following results.

\section{Results}

Data analysis refers to two questionnaires at the end of the 1st and 2nd semesters of 2014. Thus, this topic is organized in: questionnaire analysis of the 1st one and analysis of the questionnaire of the 2nd one.

\subsection{Analysis of the Questionnaire of the First Semester}

The questionnaire for the 1st one was divided into two parts: quantitative and qualitative.

In the quantitative part, the questionnaire addressed three aspects, which dealt with the content of the researchers and other general aspects of the group.

Regarding the content, the questionnaire encompassed issues: the time to read the suggested texts, the general assessment of the issues, the discussions held at the meetings, the contribution to the development of research on technology in Education and Distance Education, the contribution to research project of the group, the objectives achieved, the exposure of goals, provided bibliography and the approach of the discussed topics. 
From the analysis of Figure 1, it can be seen that in general, about the time to read the discussed texts, $60 \%$ of the group members considered it-Good, $20 \%$ as-Very good and $20 \%$ as-Excellent. In an overall assessment, $20 \%$ of participants considered the content, as-Good, $20 \%$ as-Very good and $60 \%$ as-Excellent.

About the discussions held on the content worked, $20 \%$ pose as-Good, as $20 \%$-Very good and $60 \%$ as-Excellent.

Regarding the contribution of research in ICT and distance education, $40 \%$ of the members regard as-Good and $60 \%$ as-Excellent. To contribute to the research of each member of the group, $60 \%$ put as-Good, $20 \%$ asVery good and $60 \%$ as-Excellent.

On the presentation of the objectives, $25 \%$ say as-Good, $50 \%$ as-Very good, $25 \%$ as-Excellent. And if objectives were achieved, $20 \%$ of the members, pondered how-Regular, 20\% like-Good, $20 \%$ as-Very good and $40 \%$ as-Excellent.

About the bibliography provided, $60 \%$ accept as-Good and 40\% as-Excellent. Finally, the approach theme, $20 \%$ consider it-Good, $40 \%$ as-Very good and $40 \%$ as-Excellent.

In relation to the researchers, the questionnaire covered the following themes: the performance of researchers in general; encouragement to the participation of the group members; consistency in the development of the content; the form of ideas exposure.

Figure 2 shows that, on the performance of the researchers, 20\% of the group members regard as-Good, 20\% as-Very good and $40 \%$ as-Excellent.

Regarding the incentive to participate, the members responded that $20 \%$ consider it-Good, $40 \%$ as-Very good and $40 \%$ as-Excellent.

On the development of content, $20 \%$ of respondents believe it is-Good, $40 \%$ as-Very good and $40 \%$ as-Excellent. And on the exposure of ideas, the members agree that $20 \%$ is-Good, $40 \%$ as-Very good and $40 \%$ as-Excellent.

Regarding the participation, the questionnaire included: participation of the group members present at the meetings; time hours spent on contents; member own contribution.

Figure 3 shows the other issues addressed in the questionnaire: the participation of group members present at the meetings, the time hours spent on content and the member own contribution.

The participation of the group members present at the meeting, $40 \%$ of the members responded as-Good, $40 \%$ as-Very good and $20 \%$ as-Excellent.

The time hours spent on the content, $20 \%$ of the integrants consider it-Low, $20 \%$ as Good, $40 \%$ as-Very good and $20 \%$ as-Excellent.

About the member own contribution, $10 \%$ considered-Low, $40 \%$ as-Good and $50 \%$ as-Excellent.

In the qualitative part, as explained in the methodology used as CI, the beginning of qualitative questions of the questionnaire (I could have used more if...; It was great...; I did not like...; Missed... Suggestions...) and the CSD built in the first person singular, the opinions of group members, presented below.

I could have used more if... I made progress! But I could have used it more if I had participated in all meet-

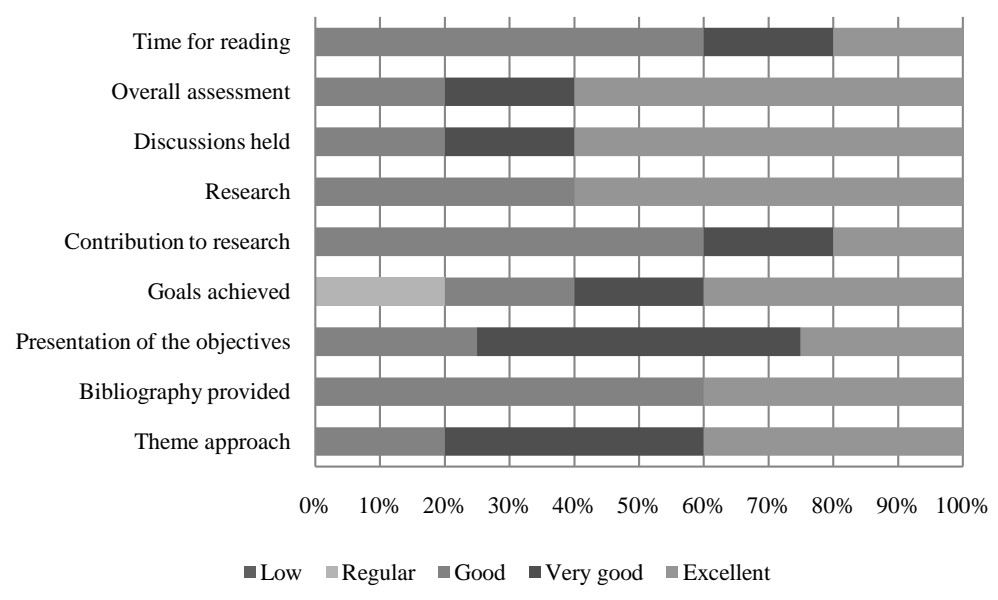

Figure 1. On the covered content. 


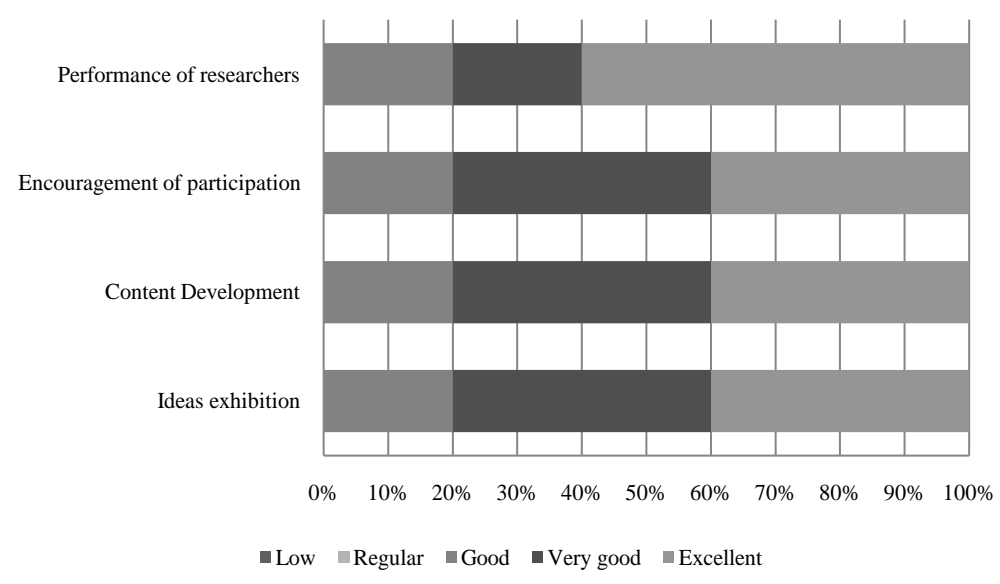

Figure 2. About the researchers.

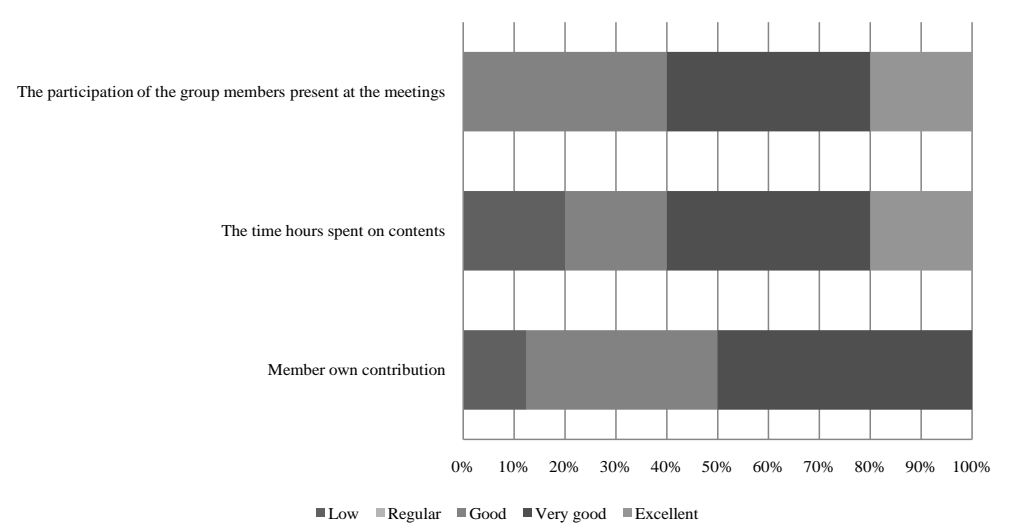

Figure 3. The participation of the group members.

ings. Also, if I had a little extra time to devote myself and exchange experiences.

It was great... Participating in the meetings, for learning and knowledge exchange.

I did not like... Not being able to participate more effectively.

Missed... Not missed anything. But I miss more communication by email and WhatsApp, because I sometimes forget to look at the Facebook group.

Suggestions... More time for studies with the group, such as readings and references on mobility and to think about new strategies of communication and information.

\subsection{Analysis of the Second Questionnaire}

Just as the questionnaires for the 1st half, the 2nd half of the questionnaire was divided into two parts: the quantitative and qualitative.

In the quantitative part, the questionnaire addressed three aspects, which dealt with the content of the researcher and other general aspects of the group.

Regarding the content, the questionnaire encompassed issues related to the time to read the suggested texts, the general evaluation of the issues, the discussions held at meetings, contribution to the development of research on technology in Education and on Distance Education, the contribution to the project from the member of the group, the achieved objectives, the exhibition of the goals, the provided bibliography and the themes approaches.

Figure 4 shows about the time for reading the texts, $10 \%$ of participants considered it-Low, as $40 \%$-Very good and 50\% as-Excellent.

On the overall evaluation of the subjects, $10 \%$ of participants considered it-Good, $20 \%$ as-Very good and $70 \%$ as-Excellent. 


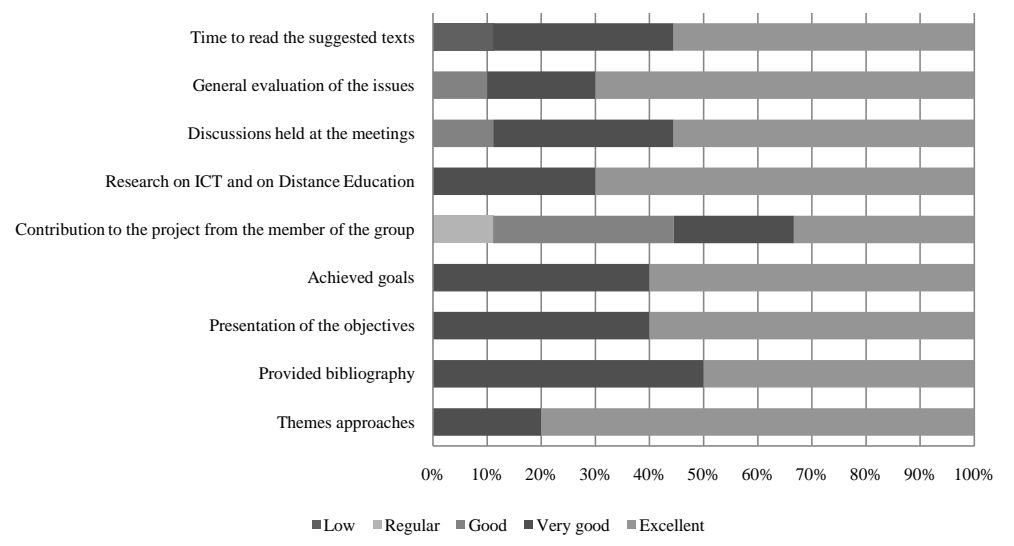

Figure 4. On the content covered.

Regarding the discussions held at the meetings, $10 \%$ of members pondered-Good, $40 \%$ as-Very good and $50 \%$ as-Excellent.

The contribution to research in the area of ICT and Distance Education, 30\% of the members responded as-Very good and $70 \%$ as-Excellent. And the contribution to research from each member, $10 \%$ of the members posed as-Regular, $30 \%$ as-Good, $20 \%$ as-Very good and $40 \%$ as-Excellent.

The objectives of lectures, $40 \%$ of participants considered-Very good and $60 \%$-Excellent. If the objectives had been achieved in the same way, $40 \%$ of participants considered-Very good and $60 \%$-Excellent.

About the provided bibliography, 50\% of members pondered-Very good and 50\%-Excellent. And on the covered topics in the lectures, $20 \%$ of participants considered-Very good and $80 \%$-Excellent.

Regarding the speakers, the questionnaire encompassed issues related to development, encouragement, consistency and exposure of ideas.

Figure 5 shows that in relation to the development of the speakers, 20\% of the group members considered it-Very good and $80 \%$ as-Excellent.

Regarding the incentives, $10 \%$ of the members responded as-Good, $20 \%$ as-Very good and $70 \%$ as-Excellent.

On consistency, $100 \%$ of the members considered as-Excellent.

Regarding the own participation of the members and group participation, the survey brought the following aspects: participation of group members in the meetings; time hours spent on contents; you contributed on which way.

The graph of Figure 6 shows that in relation to the participation of group members present at the meetings, 10\% of the members consider it-Good, 30\% as-Very good and 60\% as-Excellent.

The time hours spent on content, $10 \%$ of members rated as-Good, $70 \%$ as-Very good and $20 \%$ as-Excellent.

About their own contribution, $10 \%$ of the members regard it-Regular, $50 \%$ as-Good, $20 \%$ as-Very good and $30 \%$ as-Excellent.

In the qualitative part, as explained in the methodology used as $\mathrm{CI}$, the beginning of qualitative questions of the questionnaire (I could have used more if...; It was great...; I did not like...; Missed... Suggestions...) and the DSC we built in the first person singular, the opinions of members of the group, presented below.

I could have used more if... At the times when I've been at the meetings I made progress! But I could have taken more if I had previous access to the proposed text because I could better interact and expose more my opinions. I also think that I would have taken more if it had merged lectures and studies of scientific texts in the course of the meetings.

It was great... Participation, exchanges and reflections in the meetings. Talk, discuss and meet other speakers who brought different perspectives and issues related to technology.

I did not like... From not involving myself so much this semester.

Missed... A practical part with workshops that inter-related technologies. In addition to further study, in other words, after a presentation/lecture, to have one more days to debate and reflection on the subject.

Finally, GETED members gave some suggestions about topics they would like to have in 2015. These issues are related to teacher identity in distance education, the communities of practice, digital technologies and the 


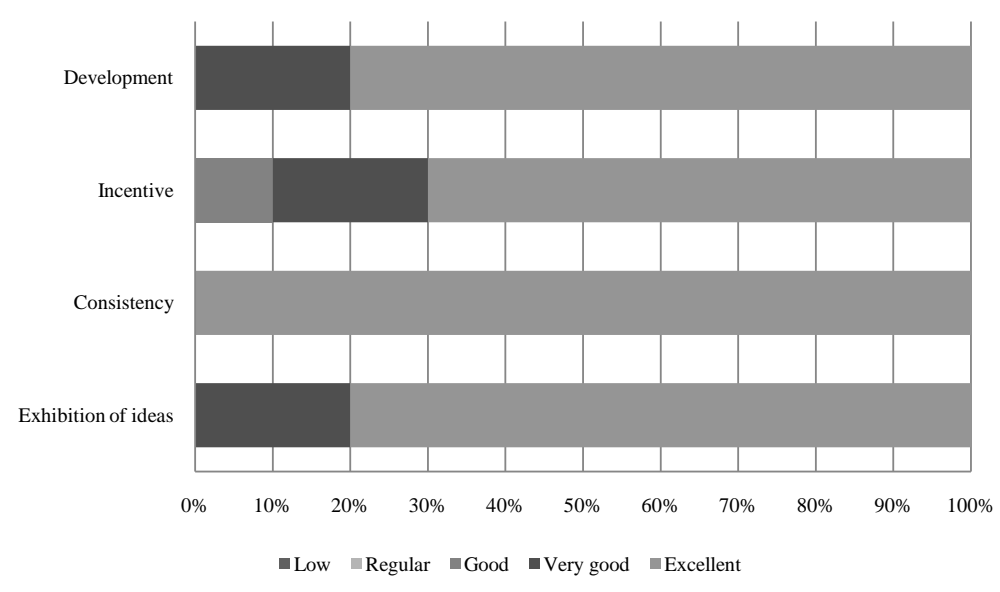

Figure 5. On the content covered.

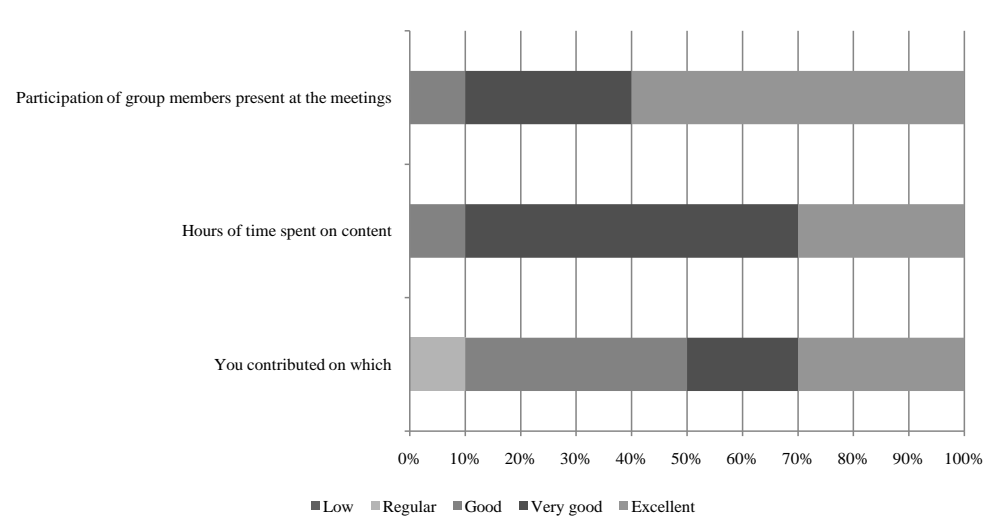

Figure 6. About participation.

students authorship, the construction of narratives, the relations between language and digital technology, qualitative analysis and interactive technologies.

\section{Analysis of Results}

From the analysis of the results of the two questionnaires it can be seen, in general, that in most of these aspects (addressed content, researchers and lecturers, participation), group members considered it-Good, Very good and/or Excellent.

In addition to this general analysis, we observed that there is a convergence point between the two questionnaires: the question of participation of GETED members.

The quantitative data showed that this participation is related to the available time to read addressed text/ content and to the own contribution of the participants in the group.

The CSD confirmed this convergence, by revealing that participants could have made more progress if they had attended all the meetings, if they had had a little too much time and greater involvement.

The word participation, according to the etymological dictionary Cunha (2010), it means "to be part of, take part in" "to convey, inform, announce".

Bordenave (1983) explains that it is possible to "part without taking part". This is the difference between passive and active participation.

From this analysis we think that some GETED members are part of this group. However, they have not yet taken part because they believe they need more time to participate in the meetings and do the required readings, to be able to collaborate with the group.

To Freire (1991), participation does not guarantee and cannot be reduced to a pure collaboration. It implies a "be present" and not just in it "be represented". It also implies the options, decisions and not only to make the 
already programmed.

Thus, Freire (2003) considers: "The participation as voice exercise, to have a voice, to interact, to decide $[\ldots] ”$.

Lave \& Weger (1991) bring another concept, from another perspective, entitled "legitimate peripheral participation". This process of participation legitimizes from the time when a member moves from the periphery of this group to its center, becoming more involved, adopting the tools and practices of the group and taking a more integral participation, which gradually increases in complexity and engagement.

From this perspective, we can also understand that although the members have not made part of the group, there may still be a process of legitimate peripheral participation in GETED.

For the peripheral participation does not mean a passive participation compared with the active participation. Legitimate peripheral participation suggests an opening, an increasing engagement process to become part of the group.

Thus, corroborating Paniago (2007), even the shares being different, the legitimate peripheral participation also has its value and can invite to reflection, as it searches learning, growth, development and a sense of involvement.

\section{Conclusion}

We end this brief survey aware that we bring contributions to initiate consideration about the GETED. We believe that we can offer an overview of the issues that we need to advance in the group: provide more time for reading and study, as well as encourage all members to take part in this group.

It should be noted that it is clear that the methodology with quantitative and qualitative approach should contribute to the analysis of the data.

Thus, to complete this article, we are aware that we need to deepen and envision other studies on the participation of GETED members: use other data collection instruments, such as the interview; explore other concepts emerged from the speech of the group members; study the role of the group on Facebook and Ning.

\section{Acknowledgements}

We thank the Programa Nacional de Pós-Doutora do (PNPD/Capes) for funding this study.

\section{References}

Gil, A. C. (1994). Methods and Techniques of Social Research. São Paulo: Atlas.

Silva, M. A. F. (2005). Methods and Research Techniques. Curitiba: Ibpex.

Lefevre, F., \& Lefevre, A. M. C. (2005). Statements and Speeches. A Proposal of Analysis in Social Research. São Paulo: Liberlivro.

Lefevre, F., \& Lefevre, A. M. C. (2012). Social Representation Research: A Quantitative and Qualitative Approach: The Collective Subject Discourse Methodology. Brasília: Liber Livro Editora.

Cunha, A. G. (2010). Etymological Dictionary of the Portuguese Language. Rio de Janeiro: Lexikon Editora.

Bordenave, J. D. (1983). What Is Participation? São Paulo: Editora Brasiliense.

Freire, P. (1991). Education in the City. São Paulo: Editora Cortez.

Freire, P. (2003). Pedagogy of the Oppressed. Rio de Janeiro: Edições Paz eTerra.

Lave, J., \& Weger, E. (1991). Situated Learning: Legitimate Peripheral Participation. New York: Cambridge University. http://dx.doi.org/10.1017/CBO9780511815355

Paniago, M. C. L. (2007). Relationships between Teachers, Students, Computer and Society in the Digital Environment, Revista Lusófona de Educação, 9, 159-171. 